\title{
Effect of Pakistan Synthetic Limited Fiber on Quality Characteristics of Khalis Limited Fiber like as Yarn Imperfection Index, Strength, CVm, and Breakage
}

\author{
Abdul Rauf Shaikh ${ }^{1}$, Hussain Bux Marri ${ }^{1}$, Rashid Ali laghari ${ }^{2}$ and Iftikhar Ali Sahito ${ }^{1,3 *}$ \\ ${ }^{1}$ Department of Industrial Engineering, Pakistan \\ ${ }^{2}$ School of Mechatronics Engineering, China \\ ${ }^{3}$ Department of Textile Engineering, Pakistan \\ *Corresponding author: Iftikhar Ali Sahito, Department of Textile Engineering, Jamshoro, Pakistan
}

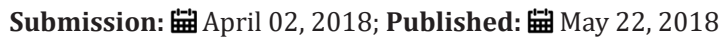

\begin{abstract}
This research paper illustrates the effect of PSL (Pakistan synthetic polyester) on yarn made by blending of Khalis fiber \& PSL polyester fiber via quality characteristics. Polyesters yarns of $30 \mathrm{Ne}$ were made on ring spinning frame at different recipes (i.e. $100 \% \mathrm{KFL}, 75 \% \mathrm{KFL}+25 \% \mathrm{PSL}$, $60 \% \mathrm{KFL}$ $+40 \% \mathrm{PSL}, 50 \% \mathrm{KFL}+50 \% \mathrm{PSL}, 40 \% \mathrm{KFL},+60 \% \mathrm{PSL}, 100 \% \mathrm{PSL}$. Yarn quality characteristics were determined for Yan imperfection index, strength, CVm and breakage experiments. Based on the Results, the effect of PSL fiber reports were made using Uster Tester 4. This research paper will focus on the quality of a product. It will focus on to set parameters like as yarn imperfection index, strength, CVm, and breakage of yarn.
\end{abstract}

Keywords: KFL Polyester fiber; PSL Polyester fiber; Ring spinning

\section{Introduction}

Ring spinning is king and outstanding process for making different types of yarns from textile fibers. No one can deny its importance till the early 1960s. Then it was felt that this process has high capital investment, high raw material cost. Therefore different experiments have been performed to make an amazing type of yarn with low raw material cost and gain high profitability range. The blending of fibers describes made with different fibers which differ in properties, with a view to achieving or improving certain characteristics of the yarn Baykal et al. [1].

The blend is an intimate mixture of staple fibers of different structure, length, diameter or color. Fabric made from the blending of yarn has better properties than made from single yarn [2]. Blending of cotton fiber with polyester fiber is done to enhance drape properties, comfort ability, dye ability and many other properties of the fabric products [3,4]. In the cotton/polyester blends, polyester fiber plays an outstanding role in all areas of the life-saving medical textiles to the geo-textiles. The plus point of polyester over other fibers is strength, luster, aesthetics properties [5]. The polyester fabric will absorb and wickless water. In order to overcome these limitations, micro-fibers were introduced to improve the polyester wick ability, and thereby dry the material quickly. When share of polyester fibers decreases in the blend, there occurs decline in yarn strength [6]. Fiber properties had unique effect on yarn strength. Blending of different fibers creates to their non-uniform distribution throughout the yarn cross-section [7].

Many researchers have been conducted research on Manmade and natural based fibers, which were manufactured from different materials such as proteins, cellulose, recycling of bottles wastes. The research has been conducted in different places and their results were also different due to different properties and Department conditions (hot, cold moisture and other properties). We analyze above all conditions are different so to prepare formula according to the customer requirements, which helps in different condition to achieve the standard quality of yarn [8-15].

\section{Materials and Method}

Polyesters yarns of $30 \mathrm{Ne}$ and $1.05 \mathrm{HR}$ were produced on ring spinning Machine (Ejm178) by using PSL, KFL polyesters with following raw material specifications given in Table 1 . Sliver in card department of 65grains was prepared by using Scutcher blow-room line and card machine (Mekin). These slivers were then fed in two passages through drawing machines i-e breaker drawing machine named Howa Breaker and finisher drawing machine (RSB D 35) to get uniformity of sliver in drawing department (Figure 1a-1g and Table 1\& 2). 


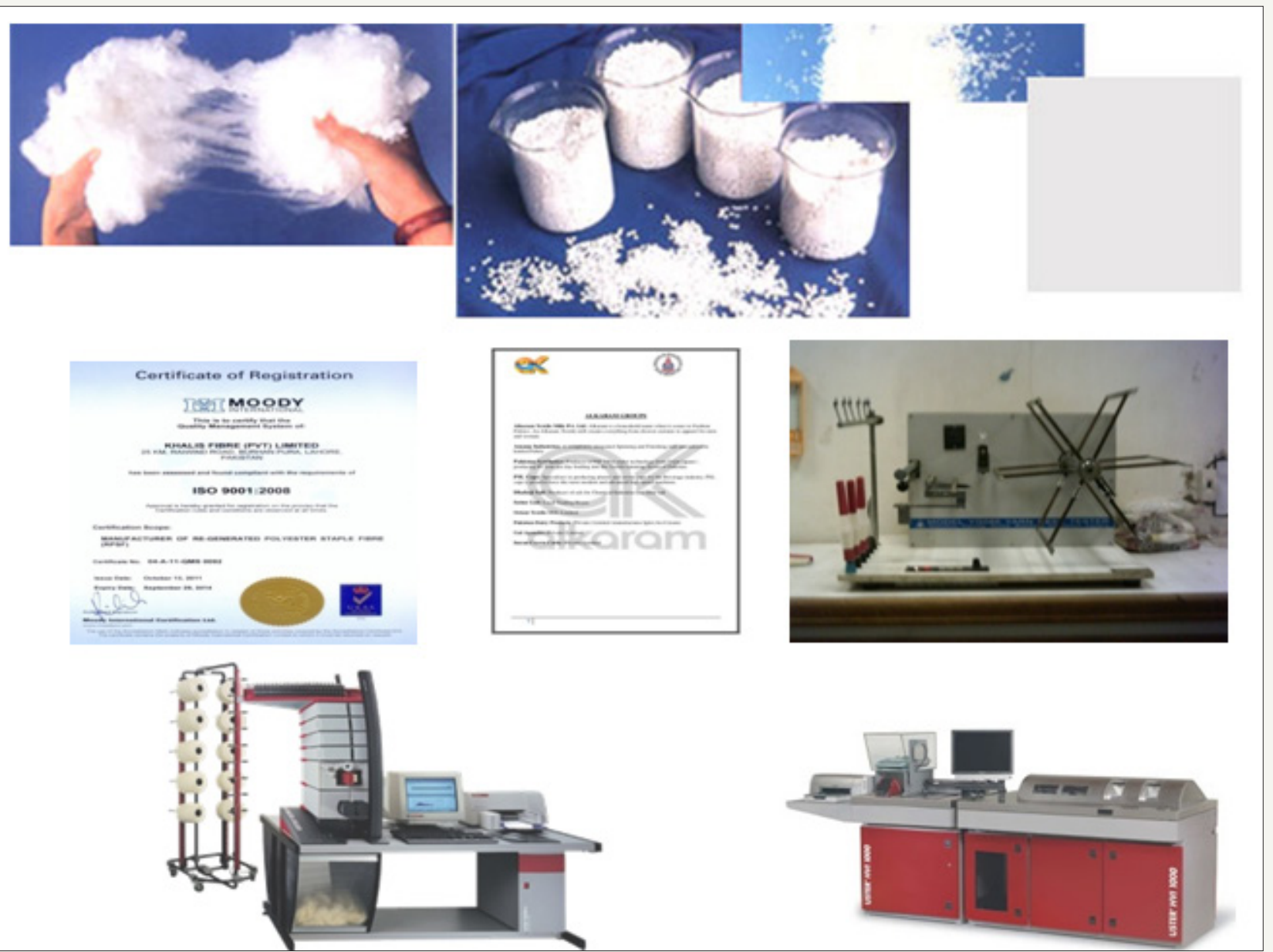

\section{Figure 1:}

1a: Khalis fiber

1b: Polyester Synthetic Fiber

1c: ISO certification of KFL fiber

1d: ISO certification pf PSL fiber

1e: Wrapping wheel

1f: UT4

1g: HVI 900.

Table 1: HVI Fiber Testing of PSL polyester, KFL polyester and China Polyester.

\begin{tabular}{|c|c|c|}
\hline Parameters & KFL Polyester & PSL Polyester \\
\hline Denier & 1.2 & 1.2 \\
\hline Length(mm) & 51 & 51 \\
\hline Type & Dull & Semi Dull \\
\hline Color R & 55 & 92 \\
\hline Color b & 45 & 8 \\
\hline No of Crimps & 4 & 13 \\
\hline Moisture\% & 0.41 & 0.39 \\
\hline Elongation\% & 15 & 24 \\
\hline Tenacity & 5 & 7 \\
\hline Shrinkage\% & 3 & 3.5 \\
\hline Grade & $\mathrm{C}$ & A \\
\hline
\end{tabular}


Table 2: Quality analysis of Yarn.

\begin{tabular}{|c|c|c|c|c|c|c|}
\hline Fiber Used & $100 \%$ KFL & $100 \%$ PSL & $75 \% \mathrm{KFL}+25 \% \mathrm{PSL}$ & $60 \% \mathrm{KFL}+40 \% \mathrm{PSL}$ & $50 \% \mathrm{KFL}+50 \% \mathrm{PSL}$ & $40 \% \mathrm{KFL}+60 \% \mathrm{PSL}$ \\
\hline Specifications & 1.2Denx $51 \mathrm{~mm}$ & 1.2Denx $51 \mathrm{~mm}$ & 1.2Denx $51 \mathrm{~mm}$ & 1.2Denx $51 \mathrm{~mm}$ & 1.2Denx $51 \mathrm{~mm}$ & 1.2Denx $51 \mathrm{~mm}$ \\
\hline Fiber Type & Polyester & Polyester & Polyester & Polyester & Polyester & Polyester \\
\hline CLSP & 3838.9 & 5053.05 & 4292 & 4564.75 & 4724.8 & 4882.35 \\
\hline $\begin{array}{l}\text { Imperfection } \\
\text { Index }\end{array}$ & 150 & 38 & 128 & 69 & 55 & 50 \\
\hline $\mathrm{CVm}$ & 15 & 11.1 & 13 & 12.9 & 12 & 11.7 \\
\hline Yarn breakage\% & $4 \%$ & $1.80 \%$ & $3.60 \%$ & $3.30 \%$ & $2.60 \%$ & $2.50 \%$ \\
\hline
\end{tabular}

\section{Results \& Discussion}

\section{Effect of PSL fiber on CLSP of Khalis fiber}

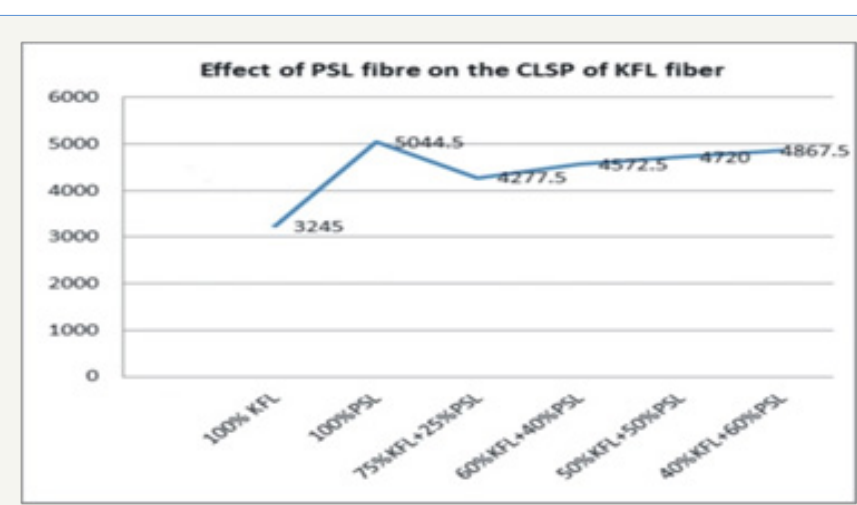

Figure 2: Effect of PSL fiber on CLSP of Khalis fiber.

Figure 2 shows the effect of PSL fiber on CLSP of Khalis fiber. As the ratio of PSL fiber increases, CLSP values also increase gradually. The minimum CLSP values are obtained at 100\%KFL, Lower CLSP values in the fiber mean less strength in the final yarn quality. As the ratio of PSL fiber increased, CLSP increased from $3300 \mathrm{lbs}$ to 5044.5lbs.

\section{Effect of PSL fiber on yarn breakage \% of Khalis fiber}

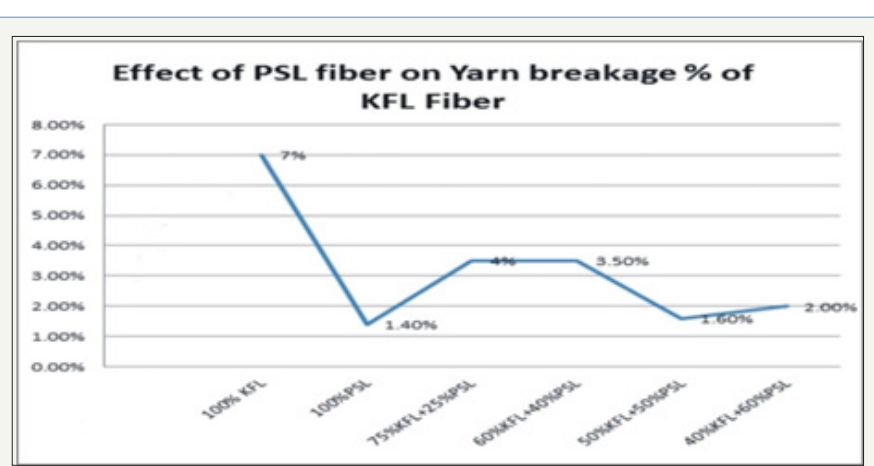

Figure 3: The effect of PSL fiber on Yarn breakage \% of Khalis fiber.

Figure 3 shows the effect of PSL fiber on Yarn breakage\% of Khalis fiber. As the ratio of PSL fiber increases, Yarn breakage $\%$ values are decreases gradually. Lower breakage \% mean's good survival of yarn at optimum speed. The minimum breakage values are obtained at $100 \%$ PSL. As the ratio of PSL fiber increased, yarn breakage $\%$ decreased $7 \%$ to $1.4 \%$.
Effect of PSL fiber on IPI of yarn of Khalis fiber

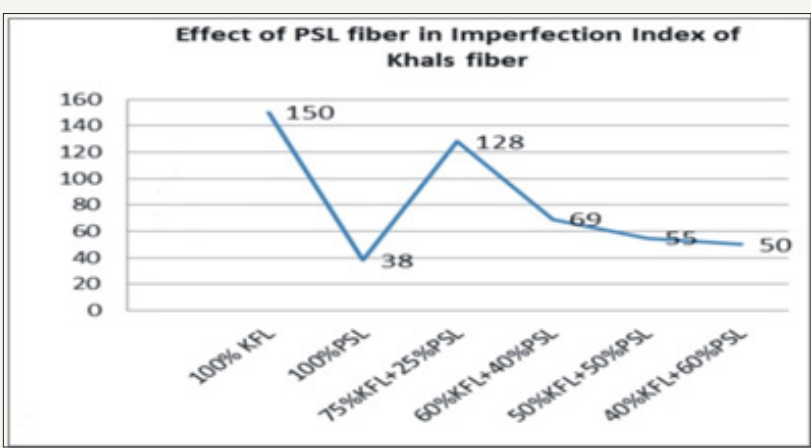

Figure 4: Effect of PSL fiber on IPI of Khalis fiber.

IPI Is Called Quality of yarn. Higher IPI values mean's Yarn quality is not good. Figure 4 shows the effect of PSL fiber on IPI of Khalis fiber. As the ratio of PSL fiber increases, IPI values also decrease gradually. Lower the number, higher the quality of yarn. The minimum IPI values are obtained at 100\%PSL. As the ratio of PSL fiber increased imperfection index values are decreased 150 to 38 .

\section{Effect of PSL fiber on Cvm of Khalis fiber}

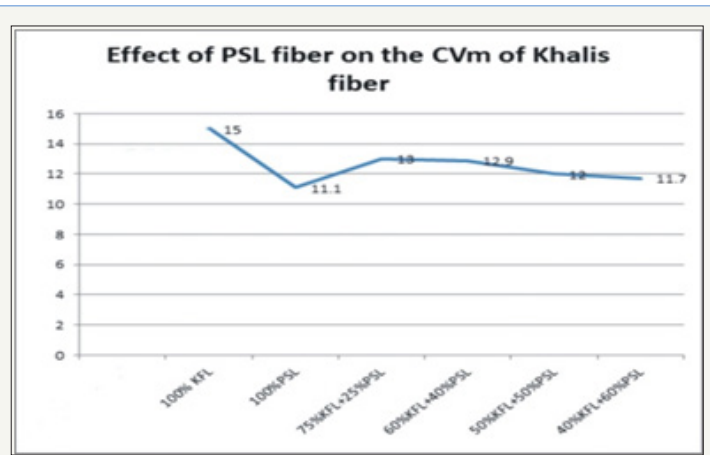

Figure 5: Effect of PSL fiber on CVm of Khalis fiber.

Figure 5 shows the effect of PSL fiber on CVm of Khalis fiber. As the ratio of PSL fiber increases, CVm values also decrease gradually. Lower the CVm, lower the deviation n mass of yarn diameter. The minimum $\mathrm{CVm}$ values are obtained at $100 \%$ PSL. Higher $\mathrm{CVm}$ mean's higher Variation in mass in yarn then quality will be not good. As the ratio of PSL fiber increased, Coefficient of variation in mass values is decreased 15 to $11.1 \%$ [16-19]. 


\section{Conclusion}

In this research paper, there was a focus on the quality of the product. It was totally focused on to set such parameters so that yarn spinning industry product properties on demand to maintain standard quality and productivity of yarn as per customer requirement. This research was conducted to investigate the final qualitative yarn via blending of PSL \& Khalis polyesters, achieving the quality parameters. Recipe of the KFL \& PSL polyesters fibers in different ratios were made to achieve the required strength and quality characteristics of China optical Qualitative yarn. From the Preformed Experiments in different ratios of PSL\& KFL fibers, it is concluded that whenever you are increasing ratio amount of PSL Polyester in KFL polyester fiber, it gets strength and more productive and qualitative. When you were performed Experiments in $75 \% \mathrm{KFL}+25 \% \mathrm{PSL}, 60 \% \mathrm{KFL}+40 \% \mathrm{PSL}, 50 \% \mathrm{KFL}+50 \% \mathrm{PSL}$ $40 \%$ KFL $+60 \%$ PSL, Yarn Strength, Yarn CVM, Yarn Breakage $\%$ and IPI quality were going better when we were increasing ratio $\%$ of PSL.

\section{Acknowledgement}

The authors would like thanks to Sr.GM of Dewan Mushtaq Textile Mills Limited Mr. Chaudry Amjad and his team. As well as especially thankful to GM of Amin/Surraya textile Mills limited for their support \& help in this research.

\section{References}

1. Baykal PD, Babaarslan O, Erol R (2006) Prediction of strength and elongation properties of cotton polyester-blended OE rotor yarns. Fibres and Textiles in Eastern Europe 14(1): 18-21.

2. Basu G, Roy AN (2008) Blending of jute with different natural fibres. Journal of Natural Fibers 4(4): 13-29.

3. Du M, Lv LB (2011) Study on structure and property of polyester/ cotton/silk three-component sirofil spun composite yarn. In Advanced Materials Research 175-176: 524-528.

4. Ibrahim DF (2014) Comparative study for improving printing of cotton/ polyester blended fabrics. Journal of Textile Science \& Engineering 4: e119.
5. Sardag S, Ozdemir 0, Kara I (2007) The effects of heat-setting on the properties of polyester/viscose blended yarns. Fibres and Textiles in Eastern Europe 63(4): 50-53.

6. Haynie DT, Khadka DB, Cross MC (2012) Physical Properties of polypeptide electrospun nanofiber cell culture scaffolds on a wettable substrate. Polymers 4(3): 1535-1553.

7. Debnath CR (1974) Some optimum conditions for the blending of jute and viscose rayon 65(7): 393-395.

8. Fan LS, Lai K, Sun RJ, Yao M (2006) Production principle of the tricomponent filament and staple fiber composite yarn. Journal of Textile Research 27(11): 40.

9. Foulk JA, Dodd RB, McAlister D, Chun D, Akin DE, et al. (2007) Flaxcotton fiber blends: miniature spinning, gin processing, and dust potential. Industrial Crops and Products 25(1): 8-16.

10. Kim HJ, Pant HR, Park CH, Tijing LD, Hwang BS, et al. (2013) Electrical properties of $\mathrm{ZnO} /$ nylon- 6 spider-wave-like nanonets prepared via electrospinning. Digest Journal of Nanomaterials and Biostructures 8(1): 385-393.

11. Lee JH, Lim KS, Hahm WG, Kim SH (2013) Properties of recycled and virgin poly (ethylene terephthalate) blend fibers. Journal of Applied Polymer Science 128(2): 1250-1256.

12. Ouchi A, Toida T, Kumaresan S, Ando W, Kato J (2010) A new methodology to recycle polyester from fabric blends with cellulose 17(1): 215-222.

13. Salim HA (2015) Performance of dyeing and printing of polyester/ viscose yarns blends for clothing use. Journal of Engineering and Computer Science 16(1).

14. Skomra E (2006) A comparative study of athletic apparel made from cotton/flax, cotton/pes, pes/flax blends. Doctoral dissertation, Thesis in Apparel, Textiles and Merchandising, Eastern Michigan University, USA.

15.Zhang JY (2012) Design and development of non-ironing fabric of cotton/fractal polyester twisted yarn. In Advanced Materials Research 418: 2235-2238.

16.http://www.khalisgroup.com/khalis-fibre.html

17. https://www.wotol.com/1-uster-tester-4-yarn-testing/second-handmachinery/prod_id/232082

18. http://textilelearner.blogspot.com/2012/10/concept-of-high-volumeinstrument-hvi_14.html

19. https://dir.indiamart.com/impcat/wrap-reel.html
Creative Commons Attribution 4.0

International License

For possible submissions Click Here

\section{Submit Article}

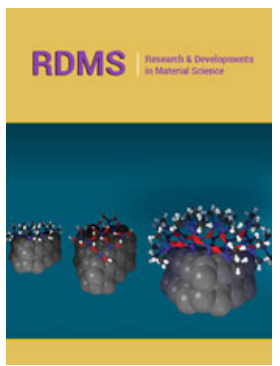

\section{Research \& Development in Material Science}

\section{Benefits of Publishing with us}

- High-level peer review and editorial services

- Freely accessible online immediately upon publication

- Authors retain the copyright to their work

- Licensing it under a Creative Commons license

- Visibility through different online platforms 